\title{
The Impact of Internal Environment of Working on the firm's performance
}

\author{
DR. AMARA Tijani \\ High Institute of Business Administration, University of Gafsa, Tunisia \\ tijani amara@yahoo.fr
}

\begin{abstract}
Research on monetary evaluation of the impact of internal environment on firm's performance always remains of importance interest. However, the validity of the results depends on the methods of evaluation and measurement used. The aim of this study is to evaluate the degradation of the firm's performance as consequence of the following two aspects: occupational accidents and injuries and the pollution of the work environment.

The first part of this paper presents a brief review of the theoretical concepts, which illustrate the relationship between the work environment and the firm's performance. The fieldwork constitutes the central arguments of the second part. The method used for the evaluation of the health damages. The results obtained stress the importance of the Health and safety issues on the performance of the firm.
\end{abstract}

\section{Key words:}

Performance, health and safety, working accident, pollution.

\section{Council for Innovative Research}

Peer Review Research Publishing System

Journal: International Journal of Management \& Information Technology

Vol. 7, No. 3

editor@cirworld.com

www.cirworld.com, member.cirworld.com 


\section{INTRODUCTION}

In an environment of increasingly competitive business the company should, more than ever, value and invest in the " empowerment " of human potential ( Argyris 2000). Ensure a work environment that allows employees to work safely and to provide the company their full energy and professional capacity must be considering among the strategic priorities of the employer.

Evaluating the overall performance of the company involves the assessment of each dimension from the assessment criteria that describing and evaluating the dimensions that it compose. Among these dimensions, the performance of the company should be considering an essential component of the overall performance of the company.

The verification of a link between the work environment and the performance of the company has been the subject of research not only for researchers of health and safety, but also for researchers of management studies. Although, this field of study is still none exploring, some researchers and industrial as well as health and safety specialists have identified links between different aspects of the work of the individual and business performance relationship. Indeed, some authors (Roy 2010; Dionne- Proulx et al, 2003; Jalette and Bergeron, 2002 James and Walters, 1999 and Nichols, 1997) observed that the health and safety has become a fundamental challenge to increase the performance of the company and an important indicator of the working conditions. Several students of management also consider the development of the individual is among the most effective to increase the performance of the company resources. For this, it should be noted that the measurement of business performance depends on the criteria selected measurement and assessment that is made of the results. But the performance is a subjective activity because it sits on indicators opted for measurement and the values of evaluators and researchers. Thus, a union can show a different employer vis-à -vis the performance measurement and industrial relations within the company point of view. Similarly, in terms of financial performance, market crises and scandals that shook the business periodically showed that «performance» of companies could overnight become «defiant» and lose their social and economic legitimacy. In addition, ISO 9000 encourages companies to integrate an effective health and safety system among its quality objectives. The standards 18001 and 18002 were preparing to make available to companies of international standards on health and safety. So, ISO standards have not only allowing the improvement of working conditions and the reduction of accidents among certified companies but they have also established links between health and safety and all productive business processes of the company. Some authors observe that the improvement of the performance of the company depends on its performance in health and safety. Longer required by the company's performance, the greater the interaction between the various components occurs, and human factors become predominant.

Indeed, the human factors work on technical factors. Occupational diseases and accidents at work increasing costs, delays and can also produce «non-quality». These are factors directly relating to productivity, where actions against absenteeism, improving the working environment, reporting relationships, working conditions and social climate of the company. If we accept that occupational diseases and accidents at work are the consequences of a malfunction of the productive system, and therefore, poor personnel management, find links between the work environment and the performance should allow now considering investment in health and safety an effective way to increase productivity and one of the best indicators of a good job.

This paper attempts to present some evidence of the significant relationship between the work environment and the performance of the company. The evidence derived from the analysis of two important elements of the work environment: the effects of pollution and the rate of accidents in the Chemical factory. The objective of the research is to assess the impact of these two factors on the performance of workers and the company. This study is characterized by modern analytical approach to the evaluation of the performance of the company, which is based on the «empowerment « of employees through participation and involvement in the management of health and safety . The first part of this paper begins with a brief review of the literature shows that the links between health and safety and business performance. This illustration is immediately following by a description of the methodology that describes the various limitations and obstacles encountered during the field research. Finally, the results of this study are presenting and discussing in the next section. The conclusion considers that the best way to ensure a good performance of the company is improving the performance of health and safety.

\section{THE THEORICAL CONCEPTS USED CONCEPTS USED AND THE NATURE OF THE RESEARCH FIELD}

The study of the relationship between the environment of working and the performance of the company responds to both the principle of fairness for workers and efficiency needs of employers. The first attempts to establish this relationship goes back to the research of Elton Mayo at Western Electric plant in Hawthorn. These studies have shown that increasing the performance of the company depends on the adaptation of employees at their workplace. Indeed, the researchers found that the improvement of working conditions and the immediate physical environment (lighting, humidity, dust and noise level ...) and the relationship between workers could make the difference in a business. These findings were confirming in the research of Frederick Herzberg witch observed that the material conditions of working occupy a position weighting among the extrinsic factors increase worker productivity. 
Despite attempts to research by management, theorists and HRM (Mamlouk, 1995; Moulinier 1998; Martory Croset, JUES 1998 and 2002), as well as some health and safety specialists, the relationship between health and safety and performance of the company remain a little of study explored area. The potential benefits of the integration of health and safety in performance of the company have been the subject of several studies in the USA (Allen, 1994 Dyjack and Levine 1995) and Canada (Ichwniowsky et al, 1996, and The Louarn Gosselin, 2000).

The most recent research (Roy, 2010; Dione -Proulx et al, 2003; Jalette and Bergeron, 2002) demonstrate the existence of links between the overall performance of the company and the improvement of working conditions and health and safety especially physical work environment. These authors find that the favorable working conditions for employees increase the economic performance of the company.

This paper analyzes, from the effects of working conditions affecting the overall performance of the company, two aspects of accidents and occupational diseases generated by the manufacturing process pollutants.

\subsection{The links between the working accidents and the overall performance of the company}

The performance measurement tends to evaluate a number of productivity indices and a number of health and safety indicators. In evaluating and measuring, the company may be deeming effective or not. These indicators are the direct costs of accidents and the effect of pollution on the performance of workers. Measuring rate of accidents is considering among the reactive measures of business performance. Indeed, the performance of this type of indicator is inversely proportional to frequency of occurrence of an accident. Nichols (1997) argues that there is a significant relationship between the accident rate and economic performance of the company. It suggests that the integration of health and safety in measuring the performance of the company reduce the number of accidents and the general working conditions therefore improve productivity and thus the overall performance of the company. The social climate also plays a crucial role in reducing accidents. Thus, the study of Jalette and Bergeron (2002) reaffirms that industrial relations have a significant impact on the economic performance of organizations.

Some researchers insist that the economic performance has always been the most important indicator of business performance. Roy (2010) found that most performance indicators designed to maximize results (revenues, profits, quantity produced). The performance of health and safety is interesting in minimizing accidents and reduce risks to an acceptable level.

Health and safety has always been considering as a direct costs that reduce the profit margin of the company as directly related to the productivity and performance of the company. However, do not forget that the health and safety has an impact on the productivity of other factors, including the quality and brand of the company.

Finally, the globalization of markets have led many companies to look to gain competitiveness and pressure to ensure the best quality and conformity of goods and products to the standards of international trade through the international certification of their activity. Indeed, the entry into force of the standards (ISO) in 1987 provides an opportunity for the company to establish links between improving the quality of their products and performance in health and safety. The integration of health and safety in ISO shows, as suggested Tekaya 1998 and Pérusse 1997, the performance and quality of goods and services must be relating to working conditions. In addition, a system of coherent and effective health and safety is likely to create a competitive advantage and have a substantial impact on the overall performance of the company.

ISO standards allowed also "Empowerment" of workers through their participation in management and their involvement in the process of total quality. Indeed, Drury (1997) found that in organizations that have "married" total quality workers are happy with the new powers that are vested and improving the work environment. Walters et al (2001) consider that the participation of workers and their representatives in the health and safety management can improve the performance of the business integration of health and safety in the productive activity of the company will reduce the exposure of workers to occupational hazards and therefore the direct and indirect costs.

In company solidarity, mobilization and social climate have a significant impact on the performance because they promote participation, training and employee incentive. Made and Bergeron consider that «the mobilization was probably more likely to have a positive impact on performance" (2002, p559)

The physical environment (climate, dust, acid) and the working atmosphere at the factory underlie carcinogens and respiratory diseases are among the causes of accidents especially during the annual shutdown period. These effects will be briefly illustrating in the following section.

\subsection{The effects of air pollution on the performance of the company}

Air pollution is, in the literal sense, a stain that affects the air. According to economist Kapp, pollution is the residue of the manufacturing process. (Kapp.k, 1963, p50) Air pollution is a very widespread problem. It has implications often underestimated the health of populations. Air pollution has many consequences. It may cause adverse effects on human health, animals, the vegetation development and condition of the materials (UNESCO, 1989, P26)

In terms of public health, the effects of air pollution are mainly, but not exclusively, the respiratory system. They are marked on sensitive populations (children, respiratory ailments, asthma, allergic subjects, and elderly). Various symptoms may occur such as difficulty of breathing, nasal and throat irritation, cough, eye irritation. The precise knowledge of the effects of air pollution on health is complex for several reasons:

- Diversity of pollutants;

- Multiple and varied exhibitions of individuals; 
- The difference in sensitivity between individuals exposed.

The pollution affects the human being himself by declining motivation, self- esteem and its environment. These effects are manifesting mainly by diseases affecting the profitability of employees and therefore the performance of the company. They can generate a negative impact on the company represented by the delay or stop production. Professional, diseases much less spectacular than the accidents was largely ignoring, but now account for a large proportion of work-related disorders. Thus, occupational diseases are costs for individuals, businesses and the community. These costs are of two types:

- The represented mainly by regulatory costs such as costs of medical services and the disruption costs as direct costs that the shortfall.

- Some expressed in terms of contributions to patients absent indirect costs. Our study focuses only on direct costs.

\subsection{Description of the research field}

The Tunisian Chemical Group is a public company whose activity is the transformation of phosphate in solid or liquid fertilizer. The factory is located $4 \mathrm{~km}$ from the area. It started in 1981 and was commissioning in March 1985. The main activity of this plant is the transformation of raw Phosphate Triple Super Phosphate primarily for export.

According to the Tunisian Agency for Environmental Protection, the measured concentrations of pollutants in the air at the plant in 2010 are presenting as follows:

Table (1) values of reference national into force of the pollutants

\begin{tabular}{|l|}
\hline Dust in suspension \\
\hline limiting Value: \\
Percentile 50 of the daily average securities during the year: \\
$80 \mu \mathrm{g} / \mathrm{m} 3$ \\
Percentile 98 of the daily average securities during the year: \\
$250 \mu \mathrm{g} / \mathrm{m} 3$ \\
Real measurement: $83 \mu \mathrm{g} / \mathrm{m} 3$ \\
\hline Carbon monoxide (CO) \\
\hline Qualitative aims: \\
Average on $8 \mathrm{~h}: 10 \mathrm{mg} / \mathrm{m} 3$. \\
Real measurement: $12 \mathrm{mg} / \mathrm{m} 3$. \\
\hline Dioxide of sulphur (SO2) \\
\hline Qualitative aim: \\
$-0,5 \mu \mathrm{g} / \mathrm{m} 3$ on annual average \\
Limiting value: \\
$-2 \mu \mathrm{g} / \mathrm{m} 3$ on average annual. \\
Real measurement: $2.4 \mu \mathrm{g} / \mathrm{m} 3$ on annual average. \\
\hline
\end{tabular}

The results listed in Table (1) show that the actual values of the pollutants emitted by the factory exceeded all the limits set by the Tunisian Agency for Environmental Protection.

\section{PRESENTATION OF THE USED METHOD AND RESULTS}

\subsection{The used method}

Several methods can be using to carry out the assessment of health costs to accidents and air pollution. However, we limit ourselves in this study using the method of damage costs. This method draws an event passage from where it is making up to the final impact in a logical sequence of steps:

- The identification of hazards of accidents and pollutants;

- The establishment of links between dangers and physical environmental factors;

- The quantitative estimation of impacts;

- The monetary estimate impacts associated to the accidents and pollution.

To determine the hazards accidents and pollutants emitted by the factory, this study holds some causes of accidents and their consequences on workers as well as indicators of pollution covered by the Tunisian Agency for environmental protection specific to the monitoring of air quality and its impact on the environment and health in particular.

For the characterization of links between physical environmental factors and health effects expected, we supposed that all employees are exposed. Thus, the relative risk is obvious and certain. In practice, the number of victims of accidents and pollutants due to the health events is calculating for each of the diseases caused. 
The identification of dangers and the characterization of the links between physical environmental factors and health effects expected, allow to quantify and monitoring the impacts on the performance of the factory.

\subsection{Presentation of the results}

This study is basing on two important sources of information. The first is basing on statistical data and monthly reports on the performance of the factory including the reports of the health and safety department. This first source of information has allowed us to identify and analyze the number of patients affected by accidents and pollutants, the monitoring to medical treatment etc...

The second source is basing on data collected during 2010 from the different departments of the factory and employees through the questionnaire developed for this reason as well as hospitals in the area. In this context, 732 questionnaires were distributing to employees. The participation rate rose $65 \%$. The results are presenting in the following table:

Table (2) Number of questionnaire distributed and collected

\begin{tabular}{|c|c|c|c|}
\hline Population & Distribue & Collecte & \% of participation \\
\hline Executives & 168 & 99 & $59 \%$ \\
\hline Employees & 564 & 377 & $67 \%$ \\
\hline Total & 732 & 476 & $65 \%$ \\
\hline
\end{tabular}

\subsubsection{Identification of diseases caused by pollutants and accidents working}

After contacting the department of health and security and analyzing the data collected from the employees, the searcher have fixed a list of diseases caused by pollutants and working accidents as follows:

Table (3) List of diseases and working accidents

\begin{tabular}{|c|c|}
\hline $\begin{array}{c}\text { Diseases due to the pollution } \\
\text { Dermatological }\end{array}$ & Falls and slips \\
\hline Respiratory & Clumsy and imprudence \\
\hline Cardiovascular & Body in the eye \\
\hline Orthopedic & Lack of protection \\
\hline O.R.L & Moving Object \\
\hline Digestive & Others actions \\
\hline
\end{tabular}

The advance analyzing of data provided by the internal infirmary of the factory shows that the approximate number of patients affected by pollution and working accidents is about 780 victims. The results are presenting in the following table:

Table (4) Classification according to the nature of diseases

\begin{tabular}{|l|l|l|l|l|}
\hline Polluants emit & Number & Causes & Number & Total \\
\hline Diseases & 86 & Falls and slips & 117 & 203 \\
\hline Dermatological & 187 & Clumsy and imprudence & 88 & 275 \\
\hline Respiratory & 13 & Body in the eye & 41 & 54 \\
\hline Cardiovascular & 32 & Lack of protection & 52 & 84 \\
\hline Orthopedic & & & & 54 \\
\hline
\end{tabular}




\begin{tabular}{|l|l|l|l|l|}
\hline O.R.L & 38 & Moving object & 22 & 60 \\
\hline Digestive & 87 & Others actions & 17 & 104 \\
\hline Total & 443 & Total & 337 & $\mathbf{7 8 0}$ \\
\hline
\end{tabular}

The researcher notes that the respiratory diseases, slip, and falls are at the forefront with a number of 304 victims. This is mainly due to the suspension of toxic gases into the atmosphere and the nature of the product produced from the factory (TSP), which facilitates the fall and slip employees. In addition, the researcher observed a significant lack of port and control of the means of protection.

Digestive Diseases and clumsy and careless occupied the second with a number of 175 victims. Indeed, the operation of machines and especially the boiler can easily cause tinnitus. The clumsy and reckless emanate mainly from the lack of concentration of workers. it comes especially when to maintenance and cleaning including the number of hours per day required is 10 hours minimum.

Dermatological diseases and lack of protection are in third place with 138 victims. Indeed, the fine particles attack the skin of employees especially those working in the phosphoric service. In addition, due to the complicity of the majority of security officials, several employees expose their health and safety by neglecting the use of protective means for prevention against risks and occupational hazards.

The data collected from the infirmary of the factory are fully consistent with the claims of employees surveyed. They argue that the conditions of the internal working environment are completely wrong. They are $86.8 \%$ to say that they are suffering of pollutants and lack of information. In this sense, $89.21 \%$ of them consider that toxic gazes and poor work organization are in fact the main cause of their suffering. According to them, the relationship between internal working conditions and their suffering is significant and very strong. The statistics confirm that the correlation coefficient is high at 0.8753 , with adjusted $\mathrm{R}^{2}$ equal to 0.8242 and a confidence level of $95 \%$. For most employees pollutants and accidents not only affect their health and productivity, but also disturb their rhythm of everyday life. They are $87.81 \%$ to say that the diseases cause suffering family.

\subsubsection{The unit of measurement}

In medical centers, the unit of measurement that reflects the actual activity for non-hospitalized cases is representing by the number of visits. However, the unit of measurement is that of the day hospital for patients living less than 24 hours and the number of admissions for those living more than 24 hours. Those units of measurement are expressing in monetary units.

In the factory, we noticed that most of the affected patients undergo medical treatment for internal infirmary. This treatment usually does not require hospitalization. Thus, the number of visits represents the unit of measurement during the period of research. For the cases transferred to the hospitals of the area, we applying the three units of measures including the number of visits, day hospital admissions for those who require hospitalization. The statistic data confirms that $43.3 \%$ of patients undergoing medical treatment in the infirmary. External hospitals occupy $56.7 \%$ of which $32.82 \%$ of treated cases require hospitalization.

\begin{tabular}{|c|c|c|c|c|c|}
\hline & & & 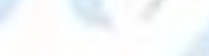 & Hospitals of th & rea \\
\hline Les victimes & Number & Infirmary & Ordinary visit & Day hospital & Days of admission \\
\hline Working accidents & 337 & 138 & 93 & 89 & 75 \\
\hline Polluants & 443 & 199 & 94 & 50 & 42 \\
\hline \multirow[b]{2}{*}{ Total } & \multirow[b]{2}{*}{780} & \multirow[b]{2}{*}{337} & 187 & 139 & 117 \\
\hline & & & \multicolumn{3}{|c|}{443} \\
\hline
\end{tabular}

\subsection{Estimation of average cost of medical treatment in the factory}

To determine the average cost of medical treatment, we should classify the costs into direct and indirect costs. These must be assigning to the various activities of health care units in order to determine the costs of medical treatment. To do this, a specific system of cost accounting in the care units seems to be necessary. This system allows providing accurate data on the costs of medical care for each patient by means of a tracking sheet. It records the nature of the disease, duration of treatment and care costs. In reality, there is currently no such system in the factory. This requires a special methodology for calculating indirect costs of care of existing diseases. Indeed, determining the average cost of medical treatment was obtaining by dividing the total actual costs of the medical center on real activity. The latter is expressing as the number of patients benefiting from services provided by the medical center. In 
cost accounting, all costs are expressing in units of work or measure. This must reflect the actual activity of the center. However, the unit of measurement that reflects the actual activity of the medical center for outpatient case is representing by the number of visits. The identification of the cost of the unit of work requires the prior determination of the overall cost of the medical center. During the research, all expenses of the medical center within the factory is presenting in following table:

Table (6) Cost investments of the center

\begin{tabular}{|c|c|}
\hline Elements of Cost & Value \\
\hline Depreciation & 4800 \\
\hline Operating Budget & 53400 \\
\hline Médicine Budget & 6800 \\
\hline Total expenses & 65000 \\
\hline Total visits all events combined (Victims of pollution, accidents and other) & 580 \\
\hline Average cost of a visit & $\mathbf{1 1 2 . 0 7 0 ~ D T}$ \\
\hline
\end{tabular}

All funds invested during the research amounted to 65000 Tunisian dinars. This amount includes all investment costs (supply and transport) and the remuneration of medical personnel and operating budgets of the center.

To evaluate the lack of performance of the factory caused by physical damage, we have used the economic values recommended by the Ministry of Public Health. Table (7) shows the average economic values for each event. Those values are the price of a regular visit by the patient, day hospital costs and the rate of hospitalization. This study was limited to data provided by the hospitals in the area only.

Table (7) the economic value of medical treatment

\begin{tabular}{|c|c|c|c|}
\hline \multicolumn{4}{|c|}{ Economic values in TND } \\
\hline Impacts on health & Visit price & Rates in Hospital daytime & Rates of admission \\
\hline Working accident & 20 & 150 & 780 \\
\hline Occupational diseases & 25 & 240 & 800 \\
\hline
\end{tabular}

Indeed, those economic values are specifying based on an agreement between the Ministry of Public Health, and National Fund for Social Security. The patient must pay according to the agreement $20 \%$ of the bill to the hospital. This will also complete invoice with one of the two cases concerned. (National Social Security Fund and the National Fund for retirement and social insurance). Thus, the hospital receives $100 \%$ of the billing rate for all cases treated medically.

\subsection{The number of admissions estimated}

To determine the total number of admissions for all diseases recorded number, we interviewed 48 medical specialists through a questionnaire asking their state the approximate number of days of hospitalization required for admission. The responses were varying, ranging from 2 days up to 15 days and that, depending on the condition being treating and the patient's medical condition. For this, we have used a weighted average number of days to determine the number of admissions. The results are presenting in the following table:

Table (8) the average number of days per admission

\begin{tabular}{|c|c|}
\hline Eléments & The weighted average number of days per admission \\
\hline Working accidents & 8.5 \\
\hline Occupational diseases & 6.23 \\
\hline
\end{tabular}

\subsection{Estimating of health costs of accidents and pollutants}

Table (9) shows the approximate health costs related to the working accidents and air pollution diseases within the factory. Those calculations was made after taking into account the average cost of medical treatment in the factory 
and the number of hospital days and admissions for victims treated in hospitals of the area. Health costs amounted to 37757.59 Tunisian dinars. The results are presenting in the following table:

Tableau (9) Health costs in within the factory

Unit: Tunisian Dinar

\begin{tabular}{|c|c|c|c|}
\hline \multirow{2}{*}{ Elements } & \multicolumn{3}{|c|}{ Infirmary of the factory } \\
\cline { 2 - 4 } & visits & Unit cost & 15455.66 \\
\hline Working accidents & 138 & 112.07 & 22301.93 \\
\hline Occupational diseases & 199 & 112.07 & 37757,59 \\
\hline Total & 337 & 112.07 & \\
\hline
\end{tabular}

However, the health costs of accident victims and pollution victims treated in the hospitals of the area amounted to 41784 dinars. This amount includes the cost of regular visits, day hospital admissions for employees who have been hospitalizing for more than 24 hours. Those figures are indeed many costs that affect not only the financial performance of the factory but also its social responsibility. The results are presenting in the following table:

Tableau (10) Health cost in the hospitals

Unit: Tunisian dinar

\begin{tabular}{|l|l|l|l|l|l|l|l|l|l|}
\cline { 2 - 10 } \multicolumn{1}{c|}{} & \multicolumn{2}{l}{ Hospitals of area } \\
\hline Diseases & Visits & $\begin{array}{l}\text { Unit } \\
\text { cost }\end{array}$ & Total & $\begin{array}{l}\text { Day } \\
\text { hospital }\end{array}$ & $\begin{array}{l}\text { Unit } \\
\text { cost }\end{array}$ & Total & Admission & $\begin{array}{l}\text { Unit } \\
\text { cost }\end{array}$ & Total \\
\hline Working accidents & 93 & 20 & 1860 & 89 & 150 & 13350 & 8.8 & 780 & 6864 \\
\hline Occupational diseases & 94 & 25 & 2350 & 50 & 240 & 12000 & 6.7 & 800 & 5360 \\
\hline Total & 187 & ----- & 4210 & 139 & ---- & 25350 & 15.5 & ---- & 12224 \\
\hline
\end{tabular}

\subsection{Estimating of the costs of the shortfall of factory's performance}

According to Mamlouk (1995), the human potential plays a very important role in improving business performance. It is with the human being that it achieved its objectives. Therefore, the employee's performance depends largely on its environmental and social climate of the company. Indeed, the productivity of the employee generally varies in the opposite direction of their health and it is evident that the overall performance of the company will be directly affecting by the decline in employee productivity. This drop can cause loss of economic performance of the company.

For the factory, the actual working is an important factor of production. This number is affecting by pollution and working accidents and therefore the productive capacity of the factory down in proportion to employee absences. In what follows, the research aims to present the steps necessary to calculate the shortfall in physical and monetary units. Based on the statistical data of health security, the total number of days lost shown in the table (11) for the period 2010 amounted to 1519 days. This number includes 683 days lost because of absences of employees affected by the pollutants and 836 days lost because of absences of employees affected by working accidents.

\begin{tabular}{|c|c|}
\hline \multicolumn{1}{|c|}{ Table (11) days lost } \\
\hline Année & $\mathbf{2 0 1 0}$ \\
\hline Total days lost & 1519 \\
\hline Working accidents & 836 \\
\hline Polluant victims & 683 \\
\hline
\end{tabular}

The diseases caused by accidents and pollutants seem numerous. Moreover, the length of absence extends more. Absences cannot be counted in days but in weeks and months. The explanatory factors of such a situation would be the extra time, which is no longer an exception but a weekly reality. Considering 8 hours per day, the number of lost due to accidents and pollutants hours amounted to 12152 hours. The results are presenting in the following table: 
Tableau (12) Hours lost

\begin{tabular}{|c|c|c|c|}
\hline Eléments & Days losted & Hours per day & Total hours lost \\
\hline Working accidents & 836 & $8 \mathrm{H}$ & $6688 \mathrm{H}$ \\
\hline Occupational diseases & 683 & $8 \mathrm{H}$ & $5464 \mathrm{H}$ \\
\hline Total & 1519 & $8 \mathrm{H}$ & $12152 \mathrm{H}$ \\
\hline
\end{tabular}

To measure the poor economic performance of the factory expressing as the amount of production lost due to accidents and pollutants, we took into account the actual production capacity of the factory. The latter is 0.306 tones in 2010. The results are presenting in the following table:

Tableau (13) The capacity production per hour

\begin{tabular}{|c|c|}
\hline Reel production (Tons) & 461963 \\
\hline Hours realised & 1536324 \\
\hline Production per hour & 0.306 \\
\hline
\end{tabular}

Based on the statistical data presented in the table (13), the shortfall in production amounted to 3718.5 tons in 2010. Table (14) shows a remarkable shortfall either tones or values. Taking into account the cost of a ton produced, the overall shortfall during the research amounted to 607688 dinars.

Table (14) The overall shortfall

\begin{tabular}{|c|c|c|c|}
\multicolumn{1}{c|}{} & Table (14) The overall shortfall \\
\cline { 2 - 4 } \multicolumn{1}{c|}{} & Working accident & Occupational diseases & Total \\
\hline Days lost & 836 & 683 & 1519 \\
\hline Hours lost & 6688 & 5464 & 12152 \\
\hline Production per hour & 0.306 & 0.306 & 0.306 \\
\hline The overall shortfall per tone & 2046.5 & 1672 & 3718.5 \\
\hline Unit cost per tonne & $163.423 \mathrm{D}$ & $163.423 \mathrm{D}$ & $163.423 \mathrm{D}$ \\
\hline Total value of overall shortfall & 334445 & 273243 & 607688 \\
\hline
\end{tabular}

In addition to the shortfall, the factory is not currently operating at full capacity. The average yield of the factory during the research amounted to $90.32 \%$. This underperformance means that the factory loses not only the shortfall generated (DT 607688) caused by poor working conditions, but also the loss of income due to under-utilization of the means of production available.

\subsection{Estimating of the overall losses due to accidents and pollutants}

All losses due to the working accidents and pollutants in the factory during the research amounted to 687229 DT. This amount includs all costs of medical treatment for victims of accidents and pollution. Those treatments were carrying out in the infirmary of the factory and the hospitals of the area. The results are presenting in the following table:

Table (15) Overall losses

\begin{tabular}{|c|c|}
\hline Costs & Montant (TND) \\
\hline Treatment costs within the factory & 37757 \\
\hline Treatment costs within the hospitals & 41784 \\
\hline The overall shortfall & 607688 \\
\hline Total & $\mathbf{6 8 7 2 2 9}$ \\
\hline
\end{tabular}


The results of this study confirm the existence of links between the performance of the factory and its performance in health and safety. Indeed the factory illustrates a waste of human potential and material resources that could be recovering to improve the overall of its performance.

\section{CONCLUSION}

The recent research on management, support the presence of links between health and safety of workers and the overall business performance. The success associated with the establishment of international standards in the field of quality (ISO-9000) and environmental protection (ISO- 14000) and the establishment of OHSAS -18001 ( Occupational Health and safety Assessment Series ) has led many companies in the world to integrate performance measurement in health and safety among the overall performance indicators.

We started with a question about environmental issues in the chemical industry to introduce the method of cost of damage of the internal health costs due to accidents and pollutants emitted by the factory. The presentation of the results confirms the remarkable costs. Moreover, on the site of the research, which has about 732 employees, working accidents and air pollution causes about 687229 dinars every year. This figure even if it is an order of magnitude, which represents about $11.32 \%$ of the profits of the factory, shows that both physical environmental factors have a significant impact on the profitability of the factory. It is reasonable therefore, to ask how the data loss can be using and interpreting in the context of the collective responsibility of the factory management to improve overall performance. Moreover, given the mode of operation of our industrial societies this supervisory role requires implementation of quantifying and monetarising elements. For the finally selected values are not simply the expression of a purely technocratic decision is still the manager to open the debate and to promote dialogue between the company and the internal participants affected by pollution. In this context, we see that the intervention to avoid the damage will only be effective with a legitimate government supported by the state.

\section{BIBLIOGRAPHY}

[1] Académie des Sciences, (1999) .Pollution atmosphérique due aux transports et santé publique. Paris, Editions Tec \& Doc, rapport commun $n^{\circ} 12$.

[2] Allen, H., (1998) .ISO 9000 paves the way to global safety worldwide goals require world-class standards, safety and health», pp 32-36.

[3] Argyris, C., (2000) .L'empowerment, dans le management des hommes. Havard Business Review, éditions organisations, Paris.

[4] Desqueyroux H., (1999). Effet à court terme de la pollution atmosphérique urbaine sur l'aggravation de l'état de santé des patients asthmatiques et insuffisants respiratoires : étude de deux panels à Paris. Thèse de Doctorat de l'Université René Descartes-Paris V.

[5] Dionne-Proulx, J, (2003). ISO 9000 et après: impact sur la performance en Heath and safety dans l'entreprise manufacturière, Montréal.

[6] Drury, C.G., (1997). Ergonomics and the quality of movement, Ergonomics. pp, 249-264.

[7] Fortin J., (1995). Questions environnementales », Accounting Ethics Journal. Montreal, Quebec.

[8] James, F. et Walters, D., (1999). Regulating health and safety at work: The way forwards. Institute of Employment Rights, London.

[9] Juès, J.P, '2002). La Gestion des ressources humaines : principes et points-cles. Ellipses, Paris.

[10] Kapp, K, William, (1963). Social Cost of Business Enterprise. Asia Publishing House., New York.

[11] Levi, D. and D. Colyer, (1974). Legal Remedies for attacking Environmental Problems. The University Press of Florida.

[12] Mamlouk, Z, (1995). De la GRH au management des hommes. Editions, CLE, Tunis.

[13] Martory, B. et Crozet, D., (1998). Gestion des ressources humaines : manuel de pilotage social. Nathan.

[14] Moulinier, R. (1998). L'évaluation du personnel : pour la démocratie dans l'entreprise. Top éditions, Paris.

[15] Nichols, T. (1997). The sociology of industrial injury. Mansell Publishing Ltd, London.

[16] Oster, Bart, D, (1983). The effects of Air Pollution on Work. Loss and Morbidity Journal of Environment Economics and Management, Vol 10, N4.

[17] Pérusse, M., (1997). Intégrer la santé et sécurité à ISO-9000 : pourquoi pas ?. Travail et Santé, juin, 13, N 2, pp 31-35.

[18] Roy, M., (2010). L'enjeu de la mesure de performance en santé et sécurité du travail, Objectif prévention. Vol. 27, N².

[19] Walters, D., (2001). The impact of trade union education and training in the health and safety on the workplace activity of health and safety representatives. HSE books, London. 